Studia i materiały z dziedzictwa kulturowego Torunia i regionu, t. 1: STARE I NOWE DZIEDZICTWO TORUNIA,

Toruń 2013

http://dx.doi.org/10.12775/SiMzDzKTiR_T1.2013.020

Małgorzata Grupa

(IARCH UMK, TORUN)

\title{
Ubiory mieszczan i szlachty z kościoła p.w. Wniebowzięcia NMP świadectwem kontaktów między Wschodem a Zachodem
}

W średniowieczu i czasach nowożytnych kościoły i cmentarze były nierozdzielne. Świątynie także pełniły funkcję stale czynnych cmentarzy i służyły do manifestowania wysokiej rangi społecznej patrycjatu oraz szlachty, podczas gdy ludzie z uboższych warstw byli grzebani na cmentarzach zlokalizowanych w wokół nich ${ }^{1}$. Badania prowadzone w latach osiemdziesiątych XX wieku w kościele p.w. Wniebowzięcia NMP w Toruniu potwierdziły istnienie cmentarza wewnątrz świątyni.

Kościół miał różnych właścicieli. Wzniesiony w średniowieczu, w XVI wieku przeszedł pod zarząd protestantów, a po „tumulcie toruńskim” wrócił do katolików. O pochówkach protestantów i katolików w kościele świadczą dowody w postaci epitafiów na ścianach kościoła, a o katolikach dowiadujemy się z Metrica Mortuorum aneksu do Kroniki Bernardynów; w identyfikacji poszczególnych zmarłych najistotniejsze są jednak informacje, umieszczone na trumnach. W przypadku materiałów z kościoła Mariackiego nie ma żadnych wątpliwości odnośnie do trzech tylko osób: Anny Maiermanówny († 1619), Zuzanny Maiermanówny $(\dagger 1623)$ oraz Tobiasza Schillinga ( $† 1666)$. Na trumnach dwóch małych sióstr znaleziono tabliczki trumienne $\mathrm{z}$ ich danymi personalnymi oraz datą śmierci ${ }^{2}$, natomiast na trumnie mężczyzny - kartusze z fragmentem mowy pogrzebowej, z której wynika, że Schilling był darczyńcą gimnazjum akademickiego w Toruniu. O pochówkach tych osób nie znajdujemy jednak informacji w dostępnych źródłach pisanych, do których zaliczany jest rejestr zmarłych ewangelickiej grupy wyznaniowej z lat 1616-1735 $5^{3}$. O Schillingu dowiadu-

1 Małgorzata GRUPA, Ubiór mieszczan i szlachty z XVI-XVIII wieku z kościoła p.w. Wniebowzięcia Najświętszej Marii Panny w Toruniu, Toruń 2005, s. 26.

2 TAMŻE, s. 54-55.

3 Arthur SEMRAU, Die Grabdenkmäler der Marienkirche, „Mitteilungen des Copernicus-Vereins für Wissenschaft und Kunst zu Thorn", H. 7, 1892, s. 1-8, 22, 58; GRUPA 2005, s. 102; Małgorzata GRUPA, Kościót Wniebowzięcia Najświętszej Marii Panny w Toruniu jako nekropolia mieszczan i szlachty, [w:] Nekropolie, kirkuty, cmentarze, red. M. OPĘCHOWSKI, Szczecin 2005, s. 39-58. 
jemy się z obszernych kazań pogrzebowych ${ }^{4}$ głoszonych na cmentarzu w czasie pogrzebu przez profesorów gimnazjum akademickiego, którzy sławili jego czyny i zasługi zarówno w życiu osobistym, jak i publicznym. Mówcy podkreślali też jego oddanie dla wiary protestanckiej ${ }^{5}$. W przypadku pochówków katolickich informacje o umieszczeniu zmarłych w tzw. „krypcie Czapskich” wcale nie są dokładniejsze. W Metrica Mortuorum znajdujemy wiadomości o pochówkach pod głównym ołtarzem a nie w krypcie, badania archeologiczne wskazują jednak na pochówki właśnie w jej obrębie ${ }^{6}$, ponieważ szczątki ludzkie, a przede wszystkim ich wyposażenie znajdujące się poza kryptą, wskazują na wcześniejsze ich złożenie (przed 1724 rokiem).

Jak wynika z powyższych informacji, tradycja chowania swoich bliskich w kościele była aktualna i dla protestantów, i dla katolików. Możliwość pochówku w świątyni mieli oczywiście jedynie ludzie bogaci, należący do patrycjatu miejskiego i do okolicznej szlachty. Dawało im to możliwość manifestowania swojej przynależności do elity społecznej, a także posiadanych zasobów materialnych. Tłumaczy to znaleziska reliktów szat jedwabnych, których według przepisów antyzbytkowych nie powinno być na szczątkach ludzkich, prawidłową i zalecaną szatę grobową stanowiła bowiem obszerna biała koszula zwana giezłem, lub biały lniany całun ${ }^{7}$.

Zapewne w tych pochówkach, gdzie zachowały się jedynie nagie ludzkie kości, zmarły ubrany był w odzież grobową, uszytą z lnu czy wełny. Tkaniny te w dość szybkim tempie ulegają rozkładowi, dlatego brak ich pozostałości w grobach. Jedwab jest znacznie bardziej odporny, stąd gdy opisujemy zachowaną odzież grobową można odnieść wrażenie, że zmarłych chowano tylko w jedwabiach. Inne tkaniny tylko w bardzo dobrych warunkach nie ulegają rozkładowi, dając możliwość rozpoznania wszystkich elementów odzieży grobowej. Tak jest w kryptach w kościele p.w. Imienia NMP w Szczuczynie, gdzie nawet możemy określić czy dana osoba została pochowana w odzieży letniej czy zimowej8.

Ubiory, wydobyte w kościele p.w. Wniebowzięcia NMP w Toruniu, są wykonane z tkanin

4 Nie wiadomo, dlaczego Semrau, publikując informacje na temat osób pochowanych w kościele, nie skorzystał z drukowanych kazań pogrzebowych, które uzupełniłyby zapewne tą listę. Być może był pewny, że wszyscy zmarli byli wpisywani do rejestru. Jednak fakty wskazują, że były to niepełne spisy. Tylko badania archeologiczne weryfikują takie nieścisłości.

5 Tobiasz SCHILLING, T. Schilling, Supremi Honoris Arrhaboquem viro genereso nobilissimo et amplissimo Tobiae Schillingio, S. R. Maj. Polon. et Svec. Secretario... Omnes et singuli in Gymnasii pariter ac Scholarum inferiorum classibus literaria stipendiam erentes, Apud Thorunenses impressit Michael Karnall, 1666, Ks. Miej. $2^{\circ} \mathrm{k}$ nlb 4.; GRUPA 2005, s. 102-104.

6 Krypta została wybudowana po przejęciu kościoła przez katolików po wydarzeniach, związanych z „tumultem toruńskim".

7 Edmund KIZIK, Śmierć w mieście hanzeatyckim w XVI-XVIII wieku. Studium z nowożytnej kultury funeralnej, Gdańsk 1998, s. 85; Paul BINSKI, Medieval death, London 2001, s. 33-47; GRUPA 2005, s. 30.

8 Małgorzata GRUPA, Pochówki w krypcie grobowej kościoła p.w. Imienia NMP w Szczuczynie jako źródło do lokalnych badań kostiumologicznych, [w:] Poza archiwalne materiały źródłowe do dziejów powiatu szczuczyńskiego w XIX wieku, red. T. DUDZIŃSKI, Grajewo 2012, s. 109 -125. W badaniach odzieży grobowej nie mieliśmy dotąd takich informacji. Czasami wydawało się, że zmarły został pochowany w za dużym odzieniu, a po analizie ubiorów ze Szczuczyna wiemy, że ocieplina wełniana miała ok. 3-5 cm grubości, po jej rozkładzie czechman czy kontusz sprawiał wrażenia zbyt dużej odzieży. 
jedwabnych'; wszystkie inne elementy przyodziewku, wykonane z płótna czy tkanin wełnianych, uległy bowiem rozkładowi. Jest to odzież męska, damska i dziecięca. Na podstawie analizy reliktów szat wydzielono dwadzieścia dwa egzemplarze odzieży. Należały do nich szustokory (il. 1) ze spodniami, dziecięce sukienki - koszulki, luźny strój zbliżony krojem do koszuli nocnej, czechmany (il. 2), żupan (il. 3, 4), kobiece suknie o cechach strojów zachodnich, pasy kontuszowe (il. 5) oraz para rękawiczek ${ }^{10}$. Według mody zachodniej uszyto szustokory, które nosili zapewne przedstawiciele patrycjatu miejskiego, a także damskie suknie i długie rękawiczki z „krypty Czapskich”. Do polskiego stroju narodowego należały czechmany, żupan i dwa pasy, które także znaleziono w krypcie. Toruńskie szaty zostały uszyte z pięknych wzorzystych jedwabi, przywiezionych najprawdopodobniej z Francji lub Włoch, zaś pasy kontuszowe pochodzą z Persji. Trudno jest określić z całą pewnością, czy dotarły one do Torunia drogą lądową czy morską.

Szaty jedwabne nosili nie tylko przedstawiciele patrycjatu toruńskiego, ale także osoby z niższych klas, które było na to stać. Potwierdzeniem tej hipotezy są przepisy antyzbytkowe, wydawane przez radę miasta w 1623, 1630 a także 1722 roku, które zakazywały noszenia odzieży uszytej z tkanin luksusowych (jedwab i najwyższej klasy wełna) przez osoby z niższych grup społecznych ${ }^{11}$. Wynika $z$ tego, że niektórzy przedstawiciele różnych rzemiosł lub handlu, posiadający znaczne majątki, ignorowali ordynacje antyzbytkowe. Ordynacje te były przeznaczone dla mieszczan Torunia, ale obejmowały też mieszkańców Mokrego i okolicznych włości. Paragraf drugi ordynacji z 1722 roku wzywał do skromności i umiaru, ale chyba nie miał zbyt dużej mocy sprawczej:

Obłoczeniem Ciał zmarłych, obiianiem trunny, y obłożeniem oneyże wieńcami, kwiatami, tudźiesz kosztewnemi rękoiesciami, żadna pompa y pycha nie ma bydź popetniona. Lecz przy Exekwiach Młodzianowy Panień nie mábydź zakazano, aby na trunne wieniec albo korona nie była położona, a w obec kazdy według stanu swego miarkowac się $\mathrm{ma}^{12}$.

O popularności w siedemnasto- i osiemnastowiecznym Toruniu jedwabnej odzieży, uszytej w stylu zachodnim, świadczą nie tylko szaty grobowe osób wyznania protestanckiego znalezione w kościele, ale także portrety z tego okresu. Na wizerunkach tych burmistrzowie miasta i profesorowie gimnazjum akademickiego mają na sobie szustokory, wykonane z wzorzystych jedwabi lub jedwabnych aksamitów. Stroje te są dodatkowo zdobione złotym

9 Małgorzata GRUPA, Konserwacja jedwabnych tkanin i rekonstrukcja szat, „Prace i Materiały Muzeum Archeologicznego i Etnograficznego w Łodzi”, Seria Numizmatyczna i Konserwatorska nr 13: 2004-2007, s. 207-218. Wydobyte relikty jedwabnych szat poddano zabiegom konserwatorskim i restauratorskim w Pracowni Dokumentacji i Konserwacji Instytutu Archeologii UMK w Toruniu.

10 GRUPA 2005, s. 48-75.

11 Romualda UZIEMBŁO, Zwyczaje pogrzebowe w XVII- $i$ XVIII-wiecznym Toruniu, [w:] Non Omnis Moriar, red. R. UZIEMBŁO, Toruń 2005, s. 4-19.

12 Zygmunt MOCARSKI, Reasumcya Ordinaciey Szlachetnego Magistratu Miasta Thorunia o szatach, weselach, chrzcinach y Pogrzebach, Rewidowana y ogłoszona, (1) lipca 1722, wyd. Z. MOCARSKI, „Tygodnik Toruński”, R. 1, nr 13, 1924, s. 2-13, (ordynacja z 1722 r., na temat pogrzebów - TAMŻE, nr 13 z 29 marca 1924 r.); UZIEMBŁO 2005, s. 5. 
haftem, w który wkomponowane są dziergane w mistrzowski sposób dziurki do guzików, a po drugiej stronie szaty - pasmanteryjne guziki. Szustokory z grobów są skromniejszą wersją tych z przedstawień ikonograficznych, ponieważ nie mają złotych haftów. Jedwabne czechmany i żupan to natomiast podręcznikowe wręcz przykłady szat, należących do polskiego stroju narodowego. Niezaprzeczalnym faktem jest, że polski strój narodowy ma swoje korzenie na Wschodzie. Ewoluował w różny sposób, ale w ostatecznej formie był to komplet, złożony z żupana jako sukni spodniej i kontusza jako okrycia zewnętrznego. Do tego należy dodać pas kontuszowy, który przewiązywano na żupanie.

Z testamentu Wojciecha Przęczkowskiego z roku 1621, pisarza JKMci mostu toruńskiego wynika nie tylko, że nosił on szaty, które zaliczono do ubioru polskiego, ale że były one wykonane częściowo z jedwabiu:

...wszystkie a wszystkie rzeczy, ktoreby kolwiek po mnie pozostały, słudze Witowi Babeckiemu Szaty moie Sukienne, Naprzod Delya lazurowa falandyszowa nowa adamaszkiem podszyta.... Potym Ferezya pułgranatowa hatlasem podszyta, potym Doloman lazurowy nowy adamaszkowy podszyty. Potym Doloma(n) Zielony nowy, Adamaszkiem czerwonym podszyty, potym Ferezya lazzurowa grzbietami lisiemi podszyta ${ }^{13}$.

Zapis ten dostarcza też dodatkowych informacji o kolorystyce tkanin używanych w tamtym okresie. Toruński żupan najprawdopodobniej był czerwony, ponieważ w trakcie prac konserwatorskich odnaleziono w szwach nici tej barwy. Został on wykonany z atłasu (il. 4), którego bardzo często używano do wykonania tego typu odzieży. W inwentarzach głównym elementem określającym rodzaj szaty jest jej barwa i nazwa, stąd dowiadujemy się o odzieży noszonej przez szlachtę i mieszczan:

...żupan adamaszkowy, czerwony z guzikami złotymi, filigranowa robota, 1 ; żupan niebieski, atłasowy, z guzikami; żupan czarny, atłasowy, z guzikami, 1; żupan adamaszkowy z guzikami stary, 1... (s. 255); ...żupan sasankowy, perubinowy, naszarzany, zł 50; żupan karmazynowy, gradeturowy, nicowany, zł $20^{14}$.

Atłasowe żupany znajdujemy w grobach dość często, różnią się one poszczególnymi elementami kroju, ale ogólnie sprawiają wrażenie szat bardzo do siebie podobnych. Różnej wysokości stójki, odmienne długości mankietów - to indywidualne cechy żupanów w poszczególnych okresach ich używania. Najwcześniej datowane żupany znaleziono w kryptach katedry

13 UZIEMBŁO 2005, s. 8-9.

14 Inwentarze mieszczańskie $z$ wieku XVIII z ksiag miejskich i grodzkich Poznania, t. 2: 1759-1793, wyd. J. BURSZTA, Cz. ŁUCZAK, Poznań 1965, s. 255, 74. 
lubelskiej ${ }^{15}$, kolejne w Lubiniu ${ }^{16}$, Gniewie $^{17}$ i Szczuczynie ${ }^{18}$. Są to zarówno szaty dorosłych, jak i dziecięce (il. 3).

Konflikt w cechu krawców w Toruniu dość dokładnie odzwierciedla stosunki, panujące pomiędzy protestantami (Niemcami) i katolikami (Polakami) w mieście. Krawcy polscy to Polacy, którzy od 1600 roku walczyli o odrębny cech przez 150 lat $^{19}$. Jeśli była to grupa walcząca z cechem, to musiała cieszyć się poparciem polskiej (katolickiej) społeczności miasta i co najważniejsze - miała zbyt na swoje wyroby. Historia konfliktów pomiędzy cechami krawców, pasamoników, szmuklerzy oraz iglarzy w Toruniu ${ }^{20}$ przynosi informacje w zakresie wytwarzanych przez nie części garderoby i dodatków do niej. Szmuklerze produkowali tylko na potrzeby stroju polskiego - tkali srebrne pasy, kręcili sznurki z nici metalicznej, którą mogli pozyskać np. z Gdańska ${ }^{21}$. Oczywiście nie rozstrzygniemy problemu, czy osoby pochowane w kościele Mariackim w Toruniu korzystały z usług miejscowych rzemieślników, ale można stwierdzić, iż miejscowe rzemiosło było przygotowane do produkcji najwytworniejszych szat ${ }^{22}$.

W kolekcji toruńskiej odzież mieszczan protestanckich była całkowicie podporządkowana tradycjom zachodnim. Zachowane portrety ukazują portrety rzemieślników cechowych, odzianych zgodnie z modą holenderską, a niektórych burmistrzów - według mody francuskiej. Portrety przedstawicieli toruńskiej elity podobne są do portretów mieszczan gdańskich czy szczecińskich ${ }^{23}$. Uwarunkowane to było przynależnością Torunia do Prus Królewskich, niemieckim pochodzeniem mieszczan oraz ich protestanckim wyznaniem, związanym całkowicie z wpływami zachodnimi. Przejmowanie i naśladowanie nowych elementów ułatwiały szerokie kontakty handlowe - zarówno z Zachodem, jak i ze Wschodem. Krzyżowały się tu kultury o całkowicie odmiennych tradycjach, jednak pewne cechy były wspólne - zamiłowanie do przepychu i okazywania swej dominacji nad innymi poprzez demonstrowanie bogactwa w ubiorze, wystawność w uroczystościach rodzinno-kościelnych. Noszenie luksusowych szat i ozdabianie się biżuterią było najprostszym sposobem na

15 Anna DRĄŻKOWSKA, Małgorzata GRUPA, Dokumentacja konserwatorska prac przeprowadzonych na zabytkach tekstylnych, metalowych i drewnianych, (mps - WOSOZ Lublin), Lublin 2002, s. 9-10; Anna DRĄŻKOWSKA, Odzież dziecięca w Polsce w XVII i XVIII wieku, Toruń 2007, s. 91-96; GRUPA 2005, s. 88.

16 Małgorzata GRUPA, The textiles the $16-18^{\text {th }}$ century from the benedictine monastery in Lubin, Leszno, [w:] Textiles in European Archaeology: Report from the $6^{\text {th }}$ NESAT Symposium, 7-1 $1^{\text {th }}$ May 1996 in Borås, „GOTARC Series” A, Vol. 1, ed. L. BENDER JØRGENSEN, C. RINALDO, Göteborg 1998, s. 287-291.

17 Małgorzata GRUPA, Sprawozdanie z badań archeologicznych w Gniewie w 2009, mps - Instytut Archeologii UMK Toruń, Toruń 2010.

18 GRUPA 2012, s. 99-108.

19 Stanisław HERBST, Toruńskie cechy rzemieślnicze, Toruń 1933, s. 145.

20 TAMŻE, s. 134.

21 Rzemieślnicy z Gdańska, ciągnący drut srebrny i złoty oraz kupcy nim handlujący przekraczali wszelkie normy przyzwoitości w ubiorze i obyczajach, w związku z czym władze Gdańska latach 1714 i 1736 wydały tylko dla nich ordynacje antyzbytkowe.

22 GRUPA 2005, s. 91.

23 Irena TURNAU, Odzież mieszczaństwa warszawskiego w XVIII wieku, Wrocław - Warszawa - Kraków 1967, s. 32 . 
wskazanie przynależności do elity społecznej. Ograniczanie dostępu do luksusu warstwom niższym poprzez ponawianie przepisów antyzbytkowych okazało się mało skuteczne w całej Europie - także w Toruniu. Bogacący się mieszczanie swobodnie korzystali z luksusowych wyrobów, nie respektując ordynacji. Patrycjat i szlachta usiłowała chociaż poprzez ubiór podkreślić swoją odrębność i wyższość klasową, jednak była to walka bezskuteczna, ponieważ bogate warstwy niższe, chociażby mistrzowie cechów i ich rodziny, swobodnie korzystali ze zbytku. Był to dość poważny problem; znajdował on swe odbicie w publikacjach z tamtego okresu. Gdański pastor Nicolaus Volckmar już na przełomie XVI/XVII wieku w swoich rozmówkach zwracał uwagę, że córki gdańskich mistrzów chodziły strojniej ubrane, niż córki burmistrzów ${ }^{24}$.

Analiza materiałów z Torunia wskazuje na dwa współistniejące kręgi kulturowe i wyznaniowe: mieszczanie to $\mathrm{w}$ większości protestanci i wpływy zachodnie, szlachta to katolicy i strój narodowy. Trudno jest ustalić, w jakim stopniu było to czytelne na ulicach miasta lub w kręgach jego elit, ponieważ przedstawienia ikonograficzne burzą ten „czysty” podział. Dla przykładu, Jakub Kazimierz Rubinkowski na portrecie wykonanym ok. 1749 roku przedstawiony jest w stroju narodowym, podczas gdy jego syn Jan Karol (zmarły dwadzieścia lat wcześniej) ubrany jest w szustokor i nie ma wąsów, czyli nosił się raczej w stylu zachodnim, podobnie jak córka, Maria Konkordia, która wzorem innych szlachcianek przywdziewała suknie uszyte w stylu zachodnim ${ }^{25}$. Podobnie było w rodzinie Szczuków, pochowanych w krypcie w Szczuczynie. Na wizerunkach Stanisława Antoniego Szczuki († 1710) widzimy postawnego mężczyznę, odzianego w strój narodowy ${ }^{26}$. Do trumny złożono go także ubranego w jedwabny czechman i kontusz. Portret trumienny jego syna, Marcina Leopolda Szczuki ( $† 1728)$ przedstawia młodego mężczyznę ubranego w zbroję, mającego na głowie białą perukę $e^{27}$. Jego ubiór grobowy to odzież uszyta w stylu zachodnim ${ }^{28}$. Suknie zmarłych kobiet, podobnie jak w Toruniu, zostały uszyte na modłę zachodnią ${ }^{29}$. Na przykładach tych można zatem stwierdzić podziały, występujące w obrębie jednej rodziny szlacheckiej, dwa różne kręgi mody: starszyzna - strój narodowy, młodzi mężczyźni i kobiety - strój zachodni.

Analiza testamentów wskazuje, że problem był znacznie głębszy, skoro w inwentarzach szlacheckich XVIII wieku coraz częściej pojawiały się zapisy, w których obok elementów stroju narodowego znajdowały się ubiory zachodnie ${ }^{30}$. A więc Polak-Sarmata-katolik z podgoloną głową i wąsami „przebierał się” w cudzoziemski strój. Czy jednak zmieniał wtedy

24 Nicolaus VOLCKMAR, Nicolausa Volckmara Viertzig Dialogi (1612), wyd. E. KIZIK, Gdańsk 2005, s. 122-123.

25 GRUPA 2005, s. 107-110.

26 Krystyna GUTOWSKA-DUDEK, Portret polski, tradycja i świadomość historyczna, Warszawa 2012, s. 103.

27 Joanna DZIUBKOWA, Vanitas. Portret trumienny na tle sarmackich obyczajów pogrzebowych. Muzeum Narodowe w Poznaniu, listopad 1996 - luty 1997, Poznań 1996, s. 160: portret trumienny Marcina Leopolda Szczuki, własność parafii p.w. Imienia NMP w Szczuczynie.

28 Małgorzata GRUPA, Adrianna WOJCIECHOWSKA, Tomasz DUDZIŃSKI, $W$ czym do trumny - zupany, kontusze, dezabilki i inne ubiory pochowanych $w$ szczuczyńskich kryptach, [w:] Tajemnice szczuczyńskich krypt, red. T. DUDZIŃSKI, M. GRUPA, t. I, s. 99-108, Grajewo 2013.

29 GRUPA 2012, s, 109-125.

30 Jarosław DUMANOWSKI, Świat rzeczy szlachty wielkopolskiej w XVIII wieku, Toruń 2006, s. 182-219. 
swoje nawyki i obyczaje? Uważni obserwatorzy tamtych czasów, Jędrzej Kitowicz ${ }^{31}$ i Łukasz Gołębiowski ${ }^{32}$, pisali o dziwnym wyglądzie wąsatego i podgolonego szlachcica w ubiorze zachodnim. Także cudzoziemcy, obserwujący zachowania Polaków i ich obyczaje, w ten sposób komentowali te zjawiska: „Polacy przejmują natychmiast nowinki w modzie, ale niestety obyczaje pozostają bez zmian"33.

Portrety trumienne, przedstawiające protestantów z okolic Międzyrzecza, Wschowy i Leszna wskazują na osoby z upodobaniami do ubiorów zachodnich. Można więc częściowo potwierdzić, że protestanci zdecydowanie częściej nosili ubiory cudzoziemskie. W inwentarzach mieszczańskich (XVIII wiek) dużo częściej można znaleźć zapisy o odzieży typu zachodniego, niż w inwentarzach szlacheckich ${ }^{34}$.

Jak można wnioskować z tych ogólnie przedstawionych danych, trudno jest określić, jakie elementy przeważały w ubiorach mieszkańców Torunia. Czy należy przede wszystkim brać pod uwagę ich przynależność stanową czy wyznaniową? Wydaje się, że tego typu badania powinny być prowadzone dwutorowo. Zagadnienie to wymaga dużo szerszych studiów z zakresu badań źródeł pisanych, ikonograficznych i archeologicznych. Niestety skromność źródeł archeologicznych pozwala jedynie na postawienie pytań, natomiast nie pozwala na szerszą analizę.

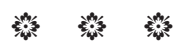

\section{Clothes of burghers and nobles excavated in the Holy Virgin Mary church - the evidence of trade contacts between the East and the West}

In Torun collection, clothes of Protestant burghers were totally subjected to western fashion traditions (justacorps), while nobles' clothing consisted of Polish national dress (żupan, czechman). Adopting western clothes was caused by Torun belonging to the Royal Prussia, German origin of Torun town dwellers and domination of Protestant religion, connected entirely with western influences. Accepting and following new elements was easy due to vivid trade contacts both with the West and East. Cultures of completely different traditions crossed in Torun, however some their features were common, i. e.: love for splendor and showing the dominance over the others demonstrating own wealth in dressing and luxury during family-church ceremonies. Wearing expensive clothes and decorating oneself with jewelry was the easiest way to indicate ones belonging to the social elite. Putting bans on luxury for lower social classes by passing various sumptuary laws turned out to be a failure in all Europe and Torun as well. The bur-

31 Jędrzej KITOWICZ, Opis obyczajów za panowania Augusta III, (wyd. II), Warszawa 1999, s. 248.

32 Łukasz GOŁĘBIOWSKI, Ubiory w Polszcze, Warszawa 1830, s. 8-16.

33 GRUPA 2005, s. 105-108.

34 DUMANOWSKI 2006, s. 190. 
ghers growing rich did not pay too much attention to Patrician families and nobles, which classes tried to emphasize their difference and class superiority by their clothes.

Territories of Poland and the Royal Prussia were the lands where fashion developed in two directions. National dress dominated among the nobles and influenced on personality shaping: Pole - Sarmatian - Catholic. In general, this definition can refer to devotion to tradition, way of dressing, shaving heads, wearing a moustache, way of living and behaving, rejecting all foreign fashion influences. However, such generalizations are not entirely true. Western impacts were so strong finding their ways into the society, that a Pole - Sarmatian could in a short time put on western garments. But the question arises, if in such a situation he also changed his habits and turned his back to old Polish traditions. Not rather, because e.g. J. Kitowicz and Ł. Gołębiowski write about strange outfit of a head-shaven noble with a moustache dressed in western garments. Post-mortem inventories also give evidence on possessing both western and Polish clothes by one man. Principal opinion on Eastern influences' supremacy over the East border part of Poland and western impacts on northern and western Polish provinces is improper if we discuss parallel men and women's fashion. We must realize the fact that women's fashion ruled its own rights and had really nothing in common with changes occurring in male Polish dress. Even the most conservative and devoted to national clothing man-noble had no influence on women way of dressing. We have two worlds in one noble's house - Eastern (Polish, Sarmatian) and the Western one, which coexist with each other under one roof. These observations are confirmed by portrait images of nobles and magnates from $17^{\text {th }}$ and $18^{\text {th }} \mathrm{c}$. The situation presented above was observed all around the country; women were faithful to western fashion accepting it uncritically with all its inconveniences. 


\section{SPIS ILUSTRACJI.}

1. Szustokor na tle schematu raportu tkaniny, fot. M. Majorek, rys. W. Matuszewska-Kola.

2. Czechman na tle schematu raportu tkaniny, fot. A. Drążkowska, rys. W. Matuszewska-Kola.

3. Żupan osoby dorosłej z Torunia i dziecka z Lublina, fot. A. Drążkowska.

4. Zdjęcie tkaniny atłasowej pod mikroskopem, fot. D. Grupa.

5. Rysunek ornamentu pasa perskiego z Torunia, rys. W. Matuszewska-Kola. 


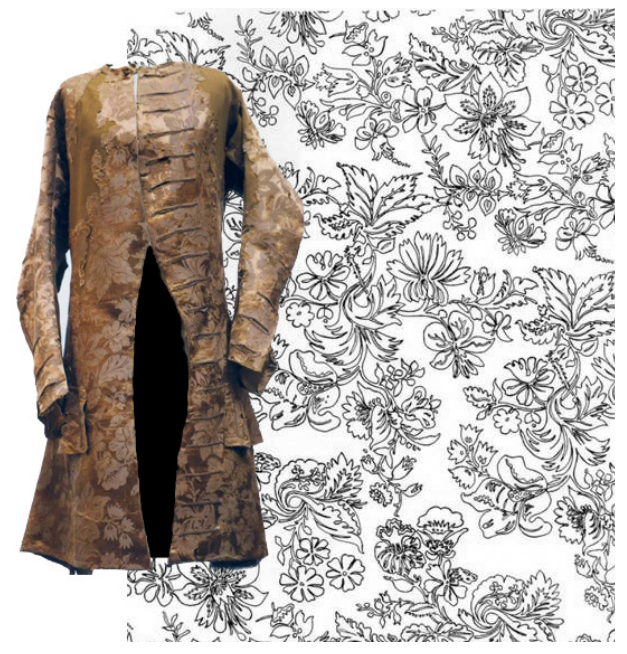

Il. 1 Szustokor na tle schematu raportu tkaniny, fot. M. Majorek, rys. W. Matuszewska-Kola

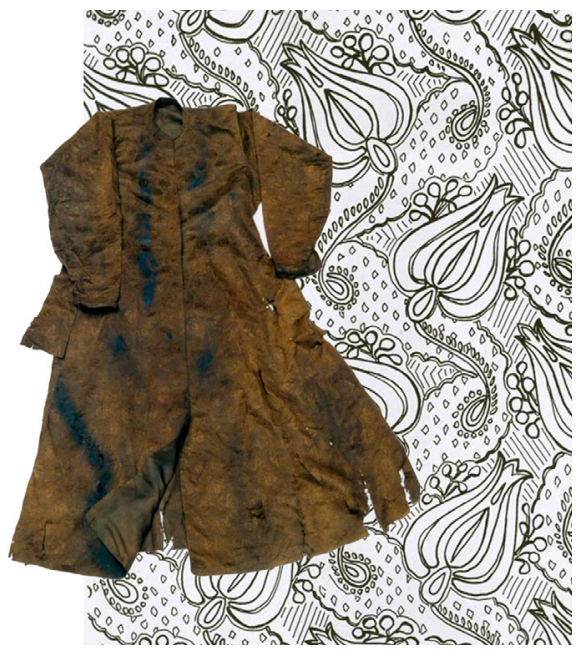

Il. 2 Czechman na tle schematu raportu tkaniny, fot. A. Drążkowska, rys. W. Matuszewska-Kola

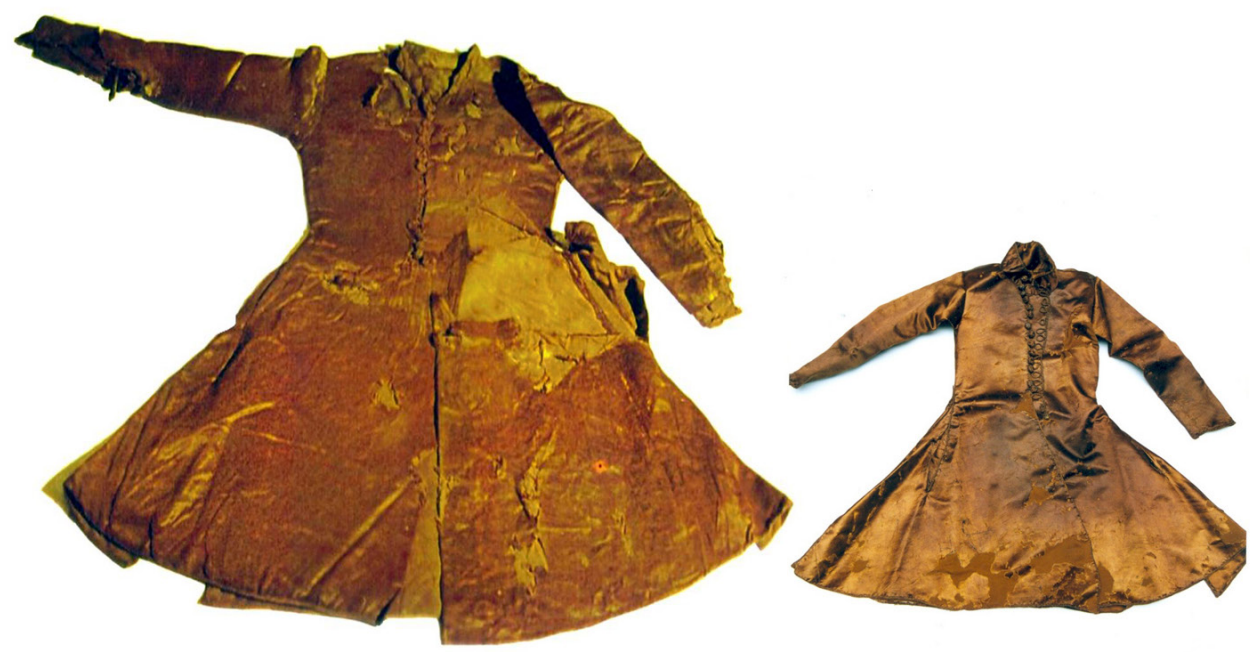

Il. 3 Żupan osoby dorosłej z Torunia i dziecka z Lublina, fot. A. Drążkowska 


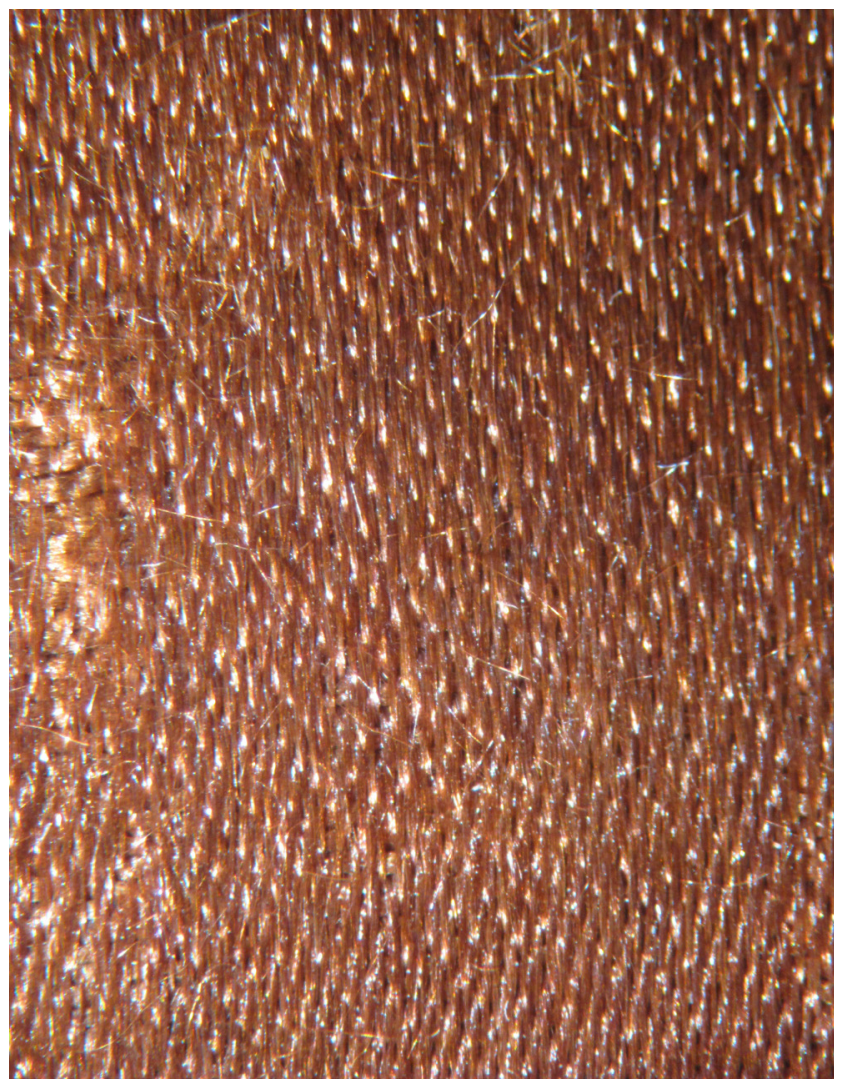

Il. 4 Zdjęcie tkaniny atłasowej pod mikroskopem, fot. D. Grupa

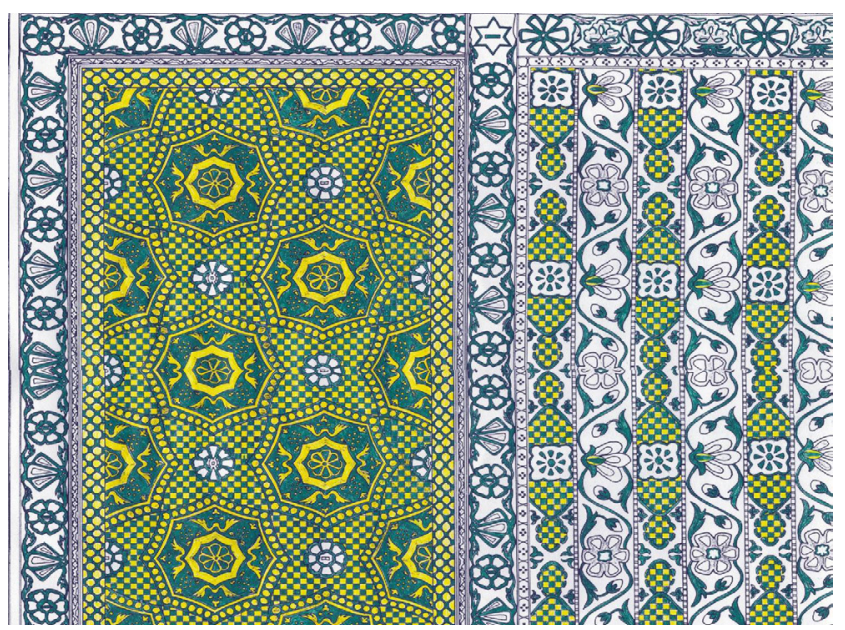

Il. 5 Rysunek ornamentu pasa perskiego z Torunia, rys. W. Matuszewska-Kola 